\title{
Correspondence
}

\section{Congenital oesophageal stenosis and herpes simplex infection}

Sir,

In the May issue of the Archives (1977, 52, 414), Valerio and co-workers report congenital oesophageal stenosis in a 7-week-old baby with swallowing difficulties. Oesophagoscopy showed a stenotic area and dilatations were successful. They mention that recurrent regurgitation had occurred during the third and fourth week, and that serological evidence of herpes simplex infection was reported in both mother and child. We believe that the latter might well be the cause of the lesion of the oesophagus. In 1973, we reported 2 cases of neonatal herpes simplex infection proved by culture and serological reactions, resulting after 5 weeks in oesophageal stenosis which was cured by dilatations (Laboureau et al., 1973). In a third observation (unpublished) a newborn had herpes vesicles in several areas of the skin (positive virus culture) and developed severe oesophagitis with a number of small ulcers and purpuric spots over the whole extent of the mucous membrane, seen by fibreoscopy. $X$-ray showed a 'congenital stenosis', but earlier the barium swallow had shown many small defects of the wall of the oesophagus, interpreted as ulcers. Topical treatment and levamisole were given and no stenosis occurred.

The oesophageal localization of neonatal herpes simplex infection seems to be a frequent occurrence (Felder et al., 1960; Langvad and Voigt, 1963; Becker et al., 1968; Miller et al., 1970), but so far most of such lesions have been found at necropsy. We emphasize that they should be routinely looked for by fibreoscopy in any baby having herpes simplex infection, and our findings support the hypothesis that they may not infrequently result in oesophageal stenosis.

A. ROSSIER, G. DE MONTIS, and J. P. CHABROLLE Service de Pédiatrie B, Hôpital Saint Vincent de Paul (Faculté de Médecine Cochin Port Royal), 74 Avenue Denfert Rochereau, 75674 Paris Cedex 14, France.

References

Becker, W., Kipps, A., and McKenzie, D. (1968). Disseminated herpes simplex infection. American Journal of Diseases of Children, 115, 1-8.

Felder, J., Muhlethaler, J.-P., and Krech, U. (1960). Herpes simplex generalisatus. Eigener Fall und kasuitischer Úberblick. (In German). Helvetica Paediatrica Acta, 15, 451-470.

Laboureau, J. P., Le Touze, P., Caldera, R., Lallemand, D., and Rossier, A. (1973). Les lésions oesophagiennes dans l'herpès néonatal. Annales de Pédiatrie (Semaine des Hôpitaux de Paris), 20, 335-340.
Langvad, A., and Voigt, J. (1963). Herpes generalisata infantum; a review and report of a new case. Danish Medical Bulletin, 10, 153-158.

Miller, D. R., Hanshaw, J. B., O'Leary, D. S., and Hnilicka, J. V. (1970). Fatal disseminated herpes simplex virus infection and hemorrhage in the neonate. Journal of Pediatrics, 76, 409-415.

Mr P. F. Jones comments:

There is no doubt that herpes simplex can affect the oesophagus and this is confirmed in some of the references which Prof. Rossier quotes. The main lesion appears to be mucosal ulceration (which can be quite widespread). This does not entirely explain why the lesion in our case was localized and, in particular, was notably elastic and resilient-a feature which seems to be typical of described cases of congenital stenosis. One would expect ulceration to be followed by fibrosis.

Whatever the aetiology of the stenosis in our patient, our main object as surgeons was to draw attention to a method of treatment which proved to be safe, simple, and effective when standard intermittent dilatation through an oesophagoscope had failed to relieve almost complete oesophageal obstruction.

$$
\begin{array}{r}
\text { PETER F. JONES } \\
\text { Royal Aberdeen Children's Hospital, } \\
\text { Cornhill Road, Aberdeen AB9 2ZG. }
\end{array}
$$

\section{Perinatal cytomegalovirus infection}

Sir,

The studies of Granström et al. (Archives, 1977, 52, 354) support the view that most perinatal cytomegalovirus (CMV) infections of infants are acquired from their mothers, but it is not possible to draw any conclusion from their data about the risk of infection from exchange transfusion in other European countries. Their high perinatal infant infection rate $(39 \%)$ is attributed to a high frequency of reactivation of the mothers' virus during pregnancy - a frequency similar to that found in the East $(18-28 \%)$ rather than that in most European and North American countries (3-4\%) (Stern, 1977). The Finnish rate of perinatal infection in normal infants could very well mask infection transmitted by exchange transfusion.

In England Tobin et al. (1975) found that $29 \%$ of 51 babies excreted CMV after exchange transfusion, whereas none of 42 nontransfused babies did so. In Oxford we found a similar increase in CMV infection of 4 out of 16 infants after exchange transfusion with blood not screened for CMV antibodies, an increase which did not occur when CMV antibody-free donations were used (unpublished results).

The hazards of CMV transmitted to infants by blood 
transfusion include the post-transfusion syndrome, hepatitis, and prolonged virus excretion by those infected. This leads in turn to infection, during the ensuing postpartum months, of those mothers who are not immune-a serious risk if this occurs at a time when the mother is again pregnant.

$$
\begin{array}{r}
\text { J. O'H. TOBIN } \\
\text { Department of Virology, } \\
\text { Churchill Hospital, } \\
\text { Oxford. } \\
\text { J. W. T. BENSON, } \\
\text { Department of Haematology, } \\
\text { The Hospital for Sick Children, } \\
\text { Great Ormond Street, London, WCIN 3JH. }
\end{array}
$$

\section{References}

Stern, H. (1977). Recent Advances in Clinical Virology, pp. 117-130. Churchill Livingstone, Edinburgh.

Tobin, J. O., MacDonald, H., and Brayshay, M. (1975). Cytomegalovirus infection and exchange transfusion. British Medical Journal, 4, 404.

\section{Dr. Granström comments :}

Our study showed only that in the transfused group of children CMV infection was no more common than in the whole group ( $3 / 7$ and $48 / 148$ respectively). No hazards were associated with CMV infection of the transfused children, or with perinatal CMV infection of the other children. The exact mechanism or source of the infection could not be identified in this study (cervical virus shedding, virus in maternal milk, etc.) but in every case of perinatal CMV infection the possibility of acquisition from the mother was present. On the other hand, seronegative pregnant women have many other possible sources of virus than their own child, because all children infected with CMV may excrete virus for a long time. $70 \%$ of perinatally infected children and $30 \%$ of all the children in our study were still excreting CMV at the age of 2 years (unpublished results).

$$
\begin{array}{r}
\text { MARJA-LIISA GRANSTRÖM } \\
\text { Children's Hospital, } \\
\text { University of Helsinki, } \\
\text { Stenbäckinkatu } 11 \text { SF-00290 Helsinki 29, Finland. }
\end{array}
$$

\section{Respiratory function after repair of congenital diaphragmatic hernia}

Sir,

The paper by Landau et al. (Archives, 1977, 52, 282) shows that there is rapid improvement in the respiratory function of the lung in infants soon after the repair of congenital diaphragmatic hernia. In a study carried out in our hospital, changes with growth in these lungs were found to be distension, emphysema, and obstruction.

A recent observation suggests that these patients should be followed for many years after the repair of the hernia. A 15-year-old boy was admitted in our department for severe chest pain related to left pneumothorax. Drainage and aspiration allowed rapid improvement and he was discharged 2 weeks later. A few days later the pneumothorax recurred. Medical treatment was unsuccessful and surgery was required to avoid another recurrence. Notably, this patient had been operated on for repair of a left congenital diaphragmatic hernia at the age of 8 months. The occurrence of pneumothorax in a distended lung 15 years after the repair of a congenital diaphragmatic hernia indicates the need for long-term follow-up of these patients.

\section{J. BATTIN, M. COLLE, and T. BECHRAOUI Sérvice de Pédiatrie et Génétique Médicale, Hôpital des Enfants, 33000 Bordeaux, France.}

\section{Sternomastoid tumour in preterm infants}

Sir,

In view of the rarity of sternomastoid tumour in preterm infants, the following cases are of interest.

Case 1. A female infant was the second born of twins to a 30-year-old primiparous mother who had been in hospital with premature rupture of the membranes and continued loss of liquor amnii for 2 weeks before delivery. Caesarean section was performed at 33 weeks' gestation. The infant was rotated by internal version for transverse lie and delivered by the breech. Birthweight was $1760 \mathrm{~g}$. She was asphyxiated, hypotonic (Apgar score 1 at 1 minute), and required intubation. Gestational assessment by modified Farr score agreed with the mother's dates. The other twin, also female, weighed $1280 \mathrm{~g}$ and was well from birth.

At age 24 days the infant was noted to have a rightsided sternomastoid tumour. Treatment was started with passive extension exercises to the affected muscle. No torticollis was noted and on review at 68 days the tumour was smaller.

Case 2. A female infant, also the second of twins, was born to a 34-year-old mother who had had one previous normal pregnancy. She was admitted to hospital at 241 weeks' gestation with spontaneous rupture of the membranes, and continued to lose liquor amnii up to 32 weeks' gestation when she went into spontaneous labour. The first infant (male, $1570 \mathrm{~g}$ ) was delivered by the vertex uneventfully.

The second twin was delivered by breech extraction. Birthweight was $1800 \mathrm{~g}$. She was asphyxiated and hypotonic (Apgar score 1 at 1 minute) and required intubation Gestational assessment agreed with the mother's dates. A tumour was noted in the left sternomastoid muscle at age 11 days. No active treatment was advised. At 65 days the tumour was smaller and was not associated with torticollis.

The aetiology of sternomastoid tumours has been discussed at length by Dunn (1974) and Jones (1968). The significance of their association with oligohydramnios, breech presentation, and other conditions predisposing to pressure effects upon the fetus suggests that they may well 